\title{
PAPER
}

\section{Production and characterization of polyetherimide mats by an electrospinning process}

To cite this article: Daniela Mitsuko Sato et al 2018 Mater. Res. Express 5115302

View the article online for updates and enhancements.

\section{IOP ebooks}

Bringing you innovative digital publishing with leading voices

to create your essential collection of books in STEM research.

Start exploring the collection - download the first chapter of every title for free. 
PAPER

CrossMark

\title{
Production and characterization of polyetherimide mats by an \\ electrospinning process
}

25 May 2018

PEVISED

21 August 2018

ACCEPTED FOR PUBLICATION

29 August 2018

PUBLISHED

7 September 2018

\author{
Daniela Mitsuko Sato ${ }^{1}$, Lília Müller Guerrini ${ }^{2,3}$ (1) Maurício Pinheiro de Oliveira $^{2}$, \\ Luís Rogério de Oliveira Hein ${ }^{1}$ and Edson Cocchieri Botelho \\ 1 Universidade Estadual Paulista Júlio de Mesquita Filho (UNESP), Department of Materials and Technology, 12516-410 - Guaratinguetá, \\ SP, Brazil \\ 2 Universidade Federal de São Paulo (UNIFESP), Department of Science and Technology, 12231-280, São José dos Campos, SP, Brazil \\ 3 Author to whom any correspondence should be addressed. \\ E-mail: daniela.mitsuko@gmail.com, guerrilili@gmail.com, mauricio.pinheiro@unifesp.br, rhein@feg.unifesp.br and \\ edson.cocchieri.botelho@gmail.com
}

Keywords: polyetherimide, electrospinning, nanofibers, non-woven mats, polymer solution

\begin{abstract}
Polyetherimide (PEI) is an amorphous, thermoplastic polymer with high heat resistance and high strength. The production of PEI fibers using electrospinning process is very attractive because this process can produce fibers with nanometric diameters, high strength and good flexibility. Polymeric solutions of PEI with 1-methyl-2-pyrrolidone (NMP) were prepared at fixed proportions (18/82, $20 / 80$ and $22 / 78 \% \mathrm{w} / \mathrm{v}$ ) and were used to produce mats using an electrospinning process. The effect of solution concentration, applied voltage and tip-to-collector distance on the properties of the PEI mats were examined. The goal of this work was to understand the effect of the various electrospinnig parameters on the properties of the PEI mats. The thermal degradation behavior, chemical structure and morphology of the PEI mats were characterized by thermogravimetric analysis (TGA), Fourier transform infrared spectroscopy (FT-IR) and scanning electron microscopy (SEM), respectively. Fibers with diameters around $150 \mathrm{~nm}$ were produced by the electrospinning and the most appropriate processing conditions were: $20 / 80 \% \mathrm{w} / \mathrm{v}$ of PEI/NMP, collector distance of $5 \mathrm{~cm}$ and voltage of $25 \mathrm{kV}$.
\end{abstract}

\section{Introduction}

Polyetherimide, from the family of polyimides, is an amorphous, thermoplastic polymer (Tg between $212{ }^{\circ} \mathrm{C}$ and $220^{\circ} \mathrm{C}$ ). This polymer has good chemical, electrical and thermal stability (degradation above $480^{\circ} \mathrm{C}$ ) as well as good mechanical properties [1]. The chemical structure of PEI consists of aromatic imides and ether units, as depicted in figure 1 . Due to its stability at high temperatures and amorphous nature, PEI has applications in many areas. This polymer can be used for printed circuit boards and hard disks for computers, under-the-hood automotive uses, in reinforced composites for aerospace applications [1], in membranes to protect magnesium alloys against corrosion [2,3] and for biohybrid organs such as the biohybrid liver support system [4].

PEI can be processed by extrusion, injection molding, casting and electrospinning $[1,5]$. Electrospinning is a technique often used to produce mats with fibers having diameters of a few nanometers and large surface area. This technique, using a polymeric solution, is done by applying an electrical potential between the solution and a ground collector.

The nanofibers in the mats produced by electrospinning have a high aspect ratio (length/diameter); high flexibility in the chemical functionality of their surfaces and good mechanical properties (tensile strength and toughness). Thus, nanostructured mats have good potential to be used as reinforcement impregnated in a composite.

The properties of the fibers, like average diameter, morphology, porosity, uniformity and mechanical properties are dependent on several parameters, including processing parameters and solution properties. 


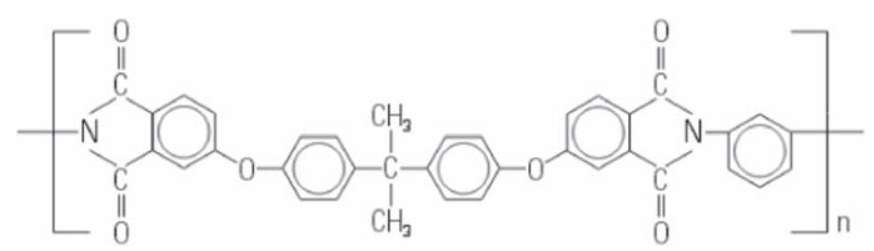

Figure 1. Chemical structure of polyetherimide (PEI) [1].

The resulting electrospun fibers can be assessed systematically by varying the main electrospinning parameters: (i) for instance, those related to the polymer: molar weight, distribution of molar weight, architecture of the polymer (linear, branched); (ii) the properties of the polymeric solution: viscosity, conductivity, dielectric constant, superficial tension and charge of the jet; (iii) the process parameters: electric potential, solution feeding rate, solution concentration, needle diameter and distance between the capillary (or tip) and the collector (known as working distance, WD); and (iv) the environment parameters: temperature, moisture and exhaust hoods [5].

Electrospun PEI has the advantage in structural applications like composites because these nanofibers can provide better adhesion in a thermoplastic or thermoset matrix resulting in mechanical properties better than in composite made with a film reinforcement of PEI due its large surface area to volume ratio. The nanofibers of $\mathrm{PEI}$ also have malleability to conform to a variety of sizes and shapes and can be produced by electrospining directly into the material like some metal alloy or carbon mats. Thus, electrospinnig process makes possible the ability to control the nanofiber composition to achieve the desired properties.

Given the industrial and scientific importance of this polymer, studies have been reported, to our knowledge, for at least 13 years, especially concerning the use of PEI to produce fibers and mats by electrospinning [6-14]. For instance, Han et al [6] evaluated the thermal stability of electrospun mats formed by poly (3-hydroxybutyrate-co-3-hydroxyvalerate) (PHBV)/PEI blends. They produced fibers with tape-like morphology. The authors found that with an increase in the amount of PEI, the degradation temperature of the mats increased. Seok et al [7] produced blends of PEI and poly (vinylidene fluorine) by electrospinning. Hotpressing and heat-process stretching were used on the mats to improve their mechanical properties. The treated mats, in comparison to the un-treated mats, exhibited an improvement in the mechanical strength from between 400 to $500 \%$. Lee et al [8] produced a new class of electrospun nanofiber mat-reinforced permselective composite membranes (ERC membrane) impregnating polyvinyl alcohol (PVA) into electrospun polyetherimide (PEI) nanofiber mat. The PEI nanofiber mat acted as a compliant framework to endow dimensional stability and mechanical strength. The PVA matrix, after being swelled with electrolyte solution, provided ion size $\left(\mathrm{OH}\right.$ versus $\left.\mathrm{Zn}(\mathrm{OH})_{4}^{2-}\right)$ dependent conductive pathways being this composite suitable for rechargeable zinc-air batteries. Vojtěch et al [9] evaluated the electrospun polyetherimide (PEI) nanofibres in application as sorbents for organochlorinated pesticides (hexachlorocyclohexanes and chlorobenzene). The gas chromatography/mass spectroscopy (GCMS/MS) analyses showed better performance of electrospun PEI nanofibres than three commercial SPME fibers for representatives of organochlorinated pesticides. Thus, the extraction time could be shortened from 50 to $10 \mathrm{~min}$ by switching the PEI fibre for the $100 \mu \mathrm{m}$ PDMS fiber while maintaining the required sensitivity.

Zhang et al [10] functionalized electrospun mats of poly (vinyl alcohol)/PEI with carbon disulfide to produce poly (vinyl alcohol)/dithiocarbamates (PVA/DTC). The authors evaluated the absorption of heavy metals by PVA/DTC. Moon et al [11] studied the influence of the rotation velocity of the collector, tension, solution concentration and WD on the processing of electrospun nanofibers using a solution of PEI/NMP. The authors concluded that aligned fibers in the direction of collector with diameters between 0.58 and $0.90 \mu \mathrm{m}$ could be obtained using solutions with concentrations of $20 \mathrm{wt} \%$, electrical tensions of 8 to $10 \mathrm{kV}$ and collector rotation velocity equal to $9.8 \mathrm{~m} \mathrm{~s}^{-1}$. Krasteva et al [12] produced nanofibers of PEI with adhesive proteins with the goal of obtaining better compatibility with cellular growth in wound dressings. Zhao et al [13] studied the dielectric properties of nanofibers of PEI processed by electrospinning. The authors found that the dielectric constants of PEI oriented fibers were very low with values in the range of 1.1. Fashandi and Karimi [14] evaluated the nanofibers produced by electrospinning using various solvents, including dimethylformamide (DMF), dimethylacetamide (DMAc) and NMP. The authors produced nanofibers with thicker fibers with rough surfaces and pores using NMP or DMAc as solvent.

Considering the technological importance of PEI and electrospinning, this article presents the effect of solution concentration, applied voltage and tip-to-collector distance on the production of nanofibers of PEI. The goal of this work was to understand the effect of the various parameters on the properties of PEI nanofibers 
Table 1. Processing conditions used to produce PEI fibers by electrospinning.

\begin{tabular}{|c|c|c|c|}
\hline Sample & Concentration $(\% \mathrm{w} / \mathrm{v})$ & Voltage (kV) & $\mathrm{WD}(\mathrm{cm})$ \\
\hline A1 & 18 & 15 & \multirow{9}{*}{5} \\
\hline A2 & 18 & 20 & \\
\hline A3 & 18 & 25 & \\
\hline A4 & 20 & 15 & \\
\hline A5 & 20 & 20 & \\
\hline A6 & 20 & 25 & \\
\hline A7 & 22 & 15 & \\
\hline A8 & 22 & 20 & \\
\hline A9 & 22 & 25 & \\
\hline B1 & 18 & 15 & \multirow{9}{*}{10} \\
\hline B2 & 18 & 20 & \\
\hline B3 & 18 & 25 & \\
\hline B4 & 20 & 15 & \\
\hline B5 & 20 & 20 & \\
\hline B6 & 20 & 25 & \\
\hline B7 & 22 & 15 & \\
\hline B8 & 22 & 20 & \\
\hline B9 & 22 & 25 & \\
\hline
\end{tabular}

produced by the electrospinning technique. The morphology, thermal degradation and chemical structure of the fibers were evaluated aiming to find some applications potentials of this material.

\section{Experimental}

\section{Materials}

The pellets of polyethermide used in this work (PEI Ultem ${ }^{\circledR} 1000$, melt flow index of $9 \mathrm{~g} / 10 \mathrm{~min}$ at $337^{\circ} \mathrm{C} /$ $6.6 \mathrm{kgf}$ ), were supplied by General Electric Plastics Co., Brazil and dried under vacuum before use. The solvent used was 1-methyl-2-pyrrolidone (NMP) supplied by Synth-Acessórios e Equipamentos para Laboratórios Ltda, Brazil.

\section{Preparation and characterization of the PEI/NMP solutions}

Solutions containing different proportions of PEI/NMP (18/82, 20/80 and 22/78\% w/v) were prepared at $70{ }^{\circ} \mathrm{C}$ under constant stirring for $2-4 \mathrm{~h}$. The dissolution time depended on the concentration of the solution. After dissolution, the concentration was determined by gravimetric analysis at $210{ }^{\circ} \mathrm{C}$. The viscosities of the solutions were evaluated at $(20 \pm 0.5){ }^{\circ} \mathrm{C}$ using a rotational rheometer, RheoStress 6000 (Thermo Scientific, Germany) with concentric cylinders geometry ( $2 \mathrm{~mm}$ gap) and shear rates between 0.1 and $100 \mathrm{~s}^{-1}$.

\section{Electrospinning}

The electrospinning of the polymeric solutions was carried out at room temperature and relative humidity $(\mathrm{RH})$ of $(55 \pm 5) \%$ with a system composed of a high voltage supply (Faísca Electronic Co., Brazil), a grounded cylindrical collector with of $20 \mathrm{~cm}$ diameter covered with aluminum foil, and a glass syringe of $20 \mathrm{ml}$ with a Hamilton needle of $0.8 \mathrm{~mm}$ diameter and $1.2 \mathrm{~mm}$ length. The applied electrical tensions were 15, 20 and $25 \mathrm{kV}$. The working distances (WD) were 5 and $10 \mathrm{~cm}$. The electrospun fibers mats of PEI were collected on the aluminum foil during $30 \mathrm{~min}$ of spinning with a collector rotation rate of $26 \mathrm{rpm}$. Table 1 shows the processing conditions to produce the PEI mats. The samples were analyzed after conditioning at $20{ }^{\circ} \mathrm{C}$ and relative humidity of $(60 \pm 5){ }^{\circ} \mathrm{C}$ for $4 \mathrm{~h}$.

\section{Fourier transform infrared (FT-IR)}

The chemical structure of the electrospun PEI was analyzed by FT-IR spectroscopy (Shimadzu Scientific Instruments Co., IR Affinity-1 Spectrometer, Japan) with a universal ATR accessory (attenuated total reflectance). All the samples were scanned in the range from 4000 to $650 \mathrm{~cm}^{-1}$ and $32 \mathrm{scans}$ per sample were collected with resolution of $2 \mathrm{~cm}^{-1}$. 


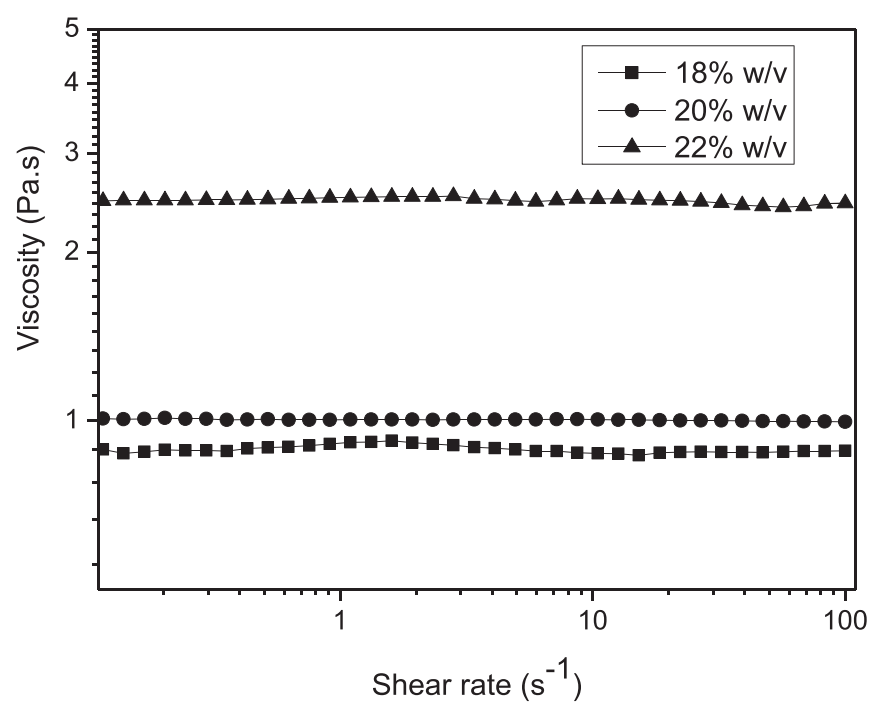

Figure 2. Viscosity of the PEI/NMP solutions at concentrations of 18, 20 and $22 \% \mathrm{w} / \mathrm{v}$.

\section{Thermogravimetric analysis (TGA)}

The thermal degradation behaviors of the mats processed at a working distance of $5 \mathrm{~cm}$ of the electrospun mats and PEI pellets were investigated using a TGA (SII Nanotech. Exstar, 6000, SEIKO Co., Japan). All analyses were conducted between $30^{\circ} \mathrm{C}$ and $700{ }^{\circ} \mathrm{C}$ at the heating rate of $10{ }^{\circ} \mathrm{C} / \mathrm{min}$ under $\mathrm{N} 2$ atmosphere. Approximately $(9.0 \pm 0.2) \mathrm{mg}$ of the samples were used for the TGA analyses.

\section{Scanning electron microscopy (SEM)}

The morphologies of the electrospun mats of PEI were observed using a scanning electron microscope (EVO LS15, Carl Zeiss). The nanofibers mats were deposited on a double-face carbon adhesive and glued to the sample holder. The average diameter of the fibers and their diameter distribution were determined by measuring a sample set of over 100 fibers selected from the SEM images using image analysis software (Image J, National Institute of Health, USA), according to the method of Ghasemi-Mobarakeh et al [15]. To confirm the existence of significant differences between the average diameters of the fibers, statistical analysis (one-way ANOVA and Tukey test) was performed to a $5 \%$ confidence level.

\section{Results and discussion}

The choice of solvent and polymer concentration is important factors that influence the solution properties of the polymer, like the viscosity and rheological behavior, which, in turn, define the electro-spinnability and influence the diameters of the obtained fibers. Figure 2 shows the viscosity analysis of PEI/NMP solutions with concentrations of 18,20 and $22 \% \mathrm{w} / \mathrm{v}$.

Newtonian behavior was exhibited by all solutions. Similar values of viscosity ( 0.9 and 1.0 Pa.s) were observed for the solutions with 18 and $20 \% \mathrm{w} / \mathrm{v}$. On the other hand, the viscosity of the $22 \% \mathrm{w} / \mathrm{v}$ of PEI solution was much higher than that of the 18 and $20 \% \mathrm{w} / \mathrm{v}$ solution. The viscosity, which is related to the solution concentration and to the interactions between polymer and solvent, is the most important parameter for the production of mats by electrospinning. Thus, to control the morphology and diameter of the mat fibers, the viscosity and rheological behavior should be taken into consideration.

The solution viscosity must support sufficient forces to elongate the drops and to form the jet in the electrospinning process. Recently, researchers have shown that Newtonian behavior of the polymer solution plays a vital role in producing mats by electrospinning using polyesters [16] and poly(D,L- lactic acid) [17]. Moon et al [11], for instance, found the viscosity values of $0.932 \mathrm{~Pa} . s$ and $1.808 \mathrm{~Pa}$.s in the solutions of PEI/NMP with 18 and $20 \mathrm{wt} \%$ PEI permitted obtaining electrospun mats. These values are very close to the viscosities measured in this work (0.9, 1.0 and 2.4 Pa.s, figure 2, for 18, 20 and 22\% of PEI).

The morphologies of the mats of the electrospun PEI produced with the concentrations of 18,20 and $22 \%$ $\mathrm{w} / \mathrm{v}$, WD of $5 \mathrm{~cm}$ and with voltages of 15, 20 and $25 \mathrm{kV}$ are shown in figures 3(a)-(i). Figures 3(j)-(m) show the morphology of the electrospun PEI processed at $20 \% \mathrm{w} / \mathrm{v}, \mathrm{WD}$ of $10 \mathrm{~cm}$ and voltages of 15, 20 and $25 \mathrm{kV}$.

The micrographs of mats of PEI processed with $18 \% \mathrm{w} / \mathrm{v}$ solution, WD $=5 \mathrm{~cm}$ and the three voltages (figures 3(a)-(c)) show fibers with numerous beads and many variations of the fiber diameter. This behavior was 


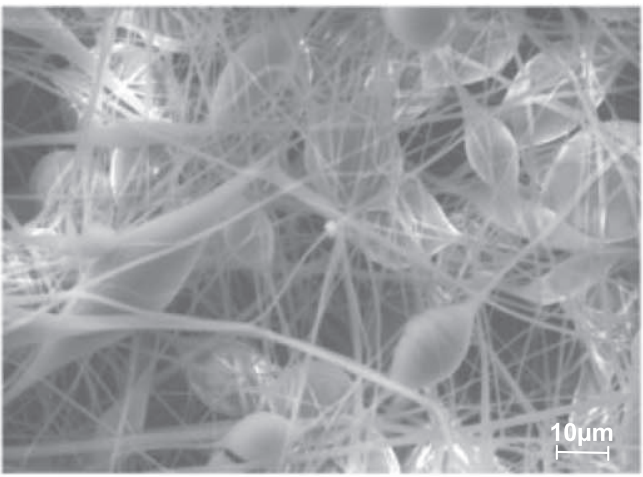

(a) $18 \% \mathrm{w} / \mathrm{v}, 15 \mathrm{kV}, \mathrm{WD}=5 \mathrm{~cm}$

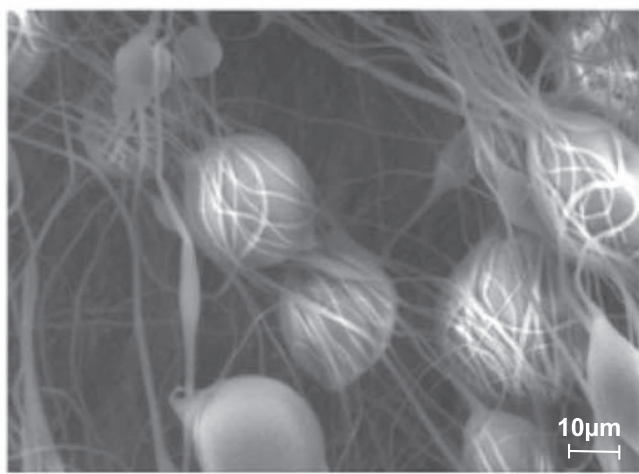

(c) $18 \% \mathrm{w} / \mathrm{v}, 25 \mathrm{kV}, \mathrm{WD}=5 \mathrm{~cm}$

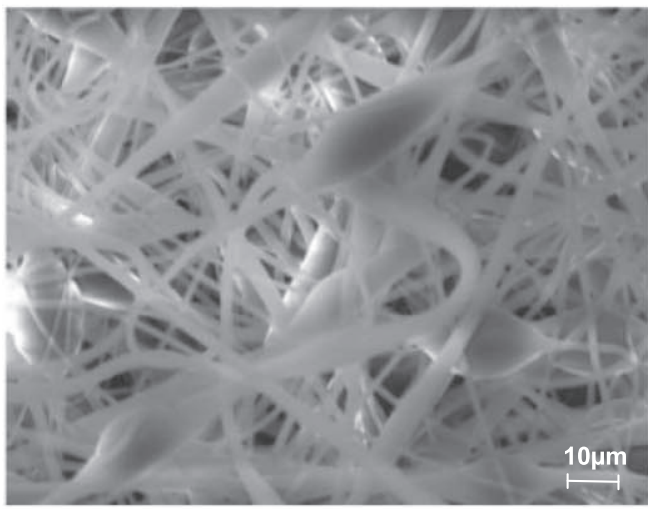

(e) $20 \% \mathrm{w} / \mathrm{v}, 20 \mathrm{kV}, \mathrm{WD}=5 \mathrm{~cm}$

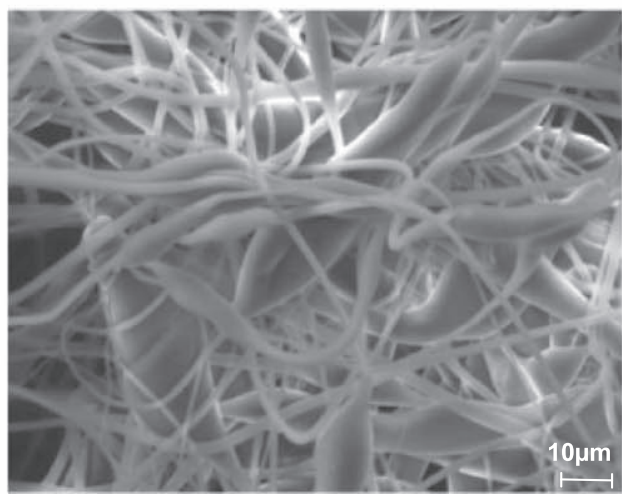

(g) $22 \% \mathrm{w} / \mathrm{v}, 15 \mathrm{kV}, \mathrm{WD}=5 \mathrm{~cm}$

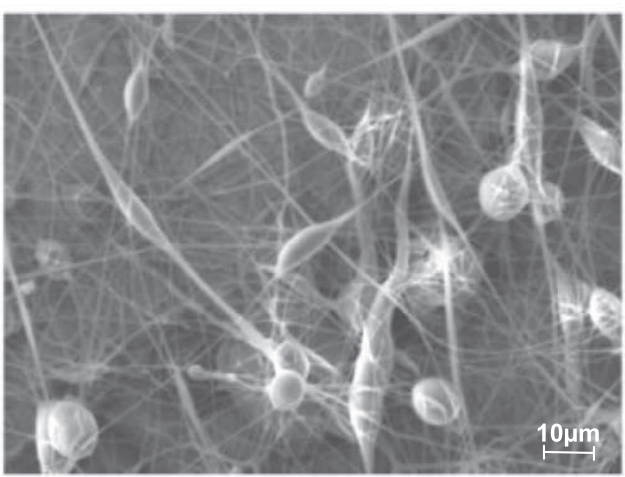

(b) $18 \% \mathrm{w} / \mathrm{v}, 20 \mathrm{kV}, \mathrm{WD}=5 \mathrm{~cm}$

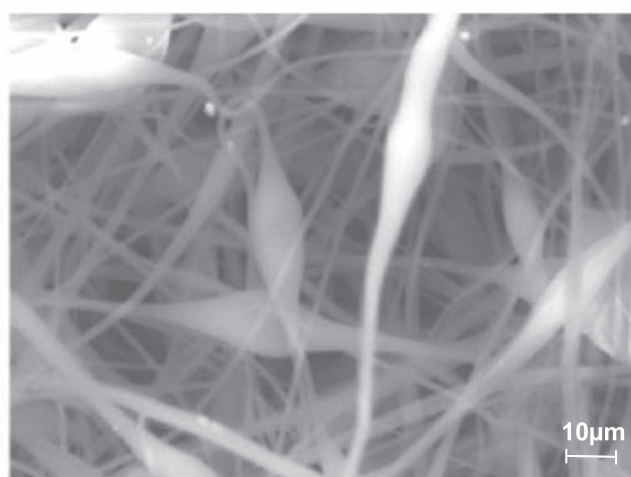

(d) $20 \% \mathrm{w} / \mathrm{v}, 15 \mathrm{kV}, \mathrm{WD}=5 \mathrm{~cm}$

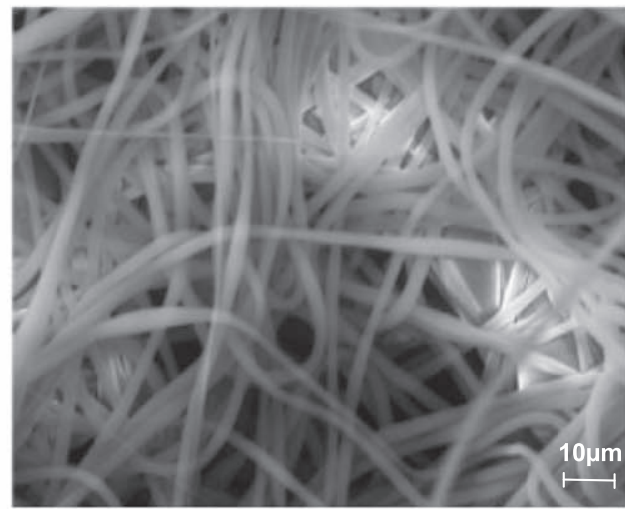

(f) $20 \% \mathrm{w} / \mathrm{v}, 25 \mathrm{kV}, \mathrm{WD}=5 \mathrm{~cm}$

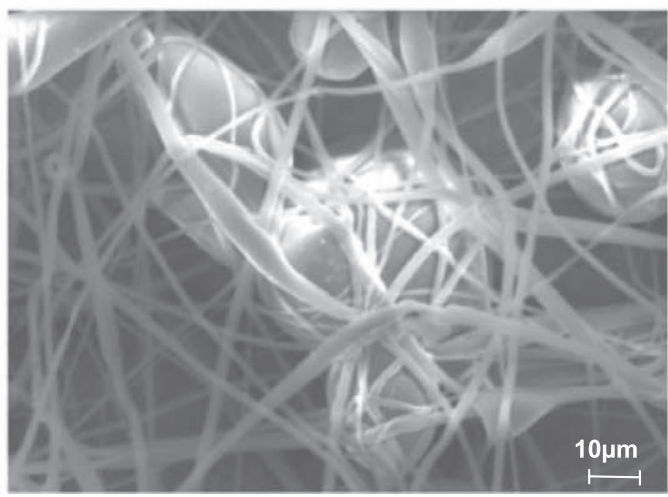

(h) $22 \% \mathrm{w} / \mathrm{v}, 20 \mathrm{kV}, \mathrm{WD}=5 \mathrm{~cm}$

Figure 3. Electrospun PEI: WD $=5 \mathrm{~cm}(\mathrm{a})-(\mathrm{i})$ and $\mathrm{WD}=10 \mathrm{~cm}(\mathrm{j})-(\mathrm{m})$.

also found in mats of PEI processed at $10 \mathrm{~cm}$ using the solution with the same concentration and the three voltages (not shown in this paper). The presence of beads is probably due to insufficient viscoelastic force on the drops to elongate and form the jet during the electrospinning process. However, for the solution of $20 \% \mathrm{w} / \mathrm{v} \mathrm{PEI}$ 


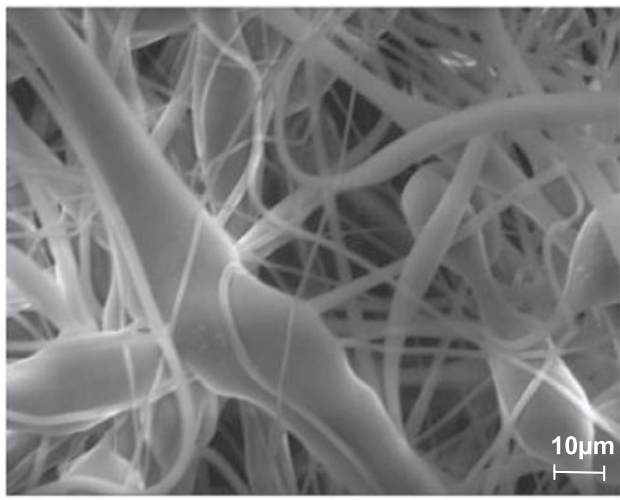

(i) $22 \% \mathrm{w} / \mathrm{v}, 25 \mathrm{kV}, \mathrm{WD}=5 \mathrm{~cm}$

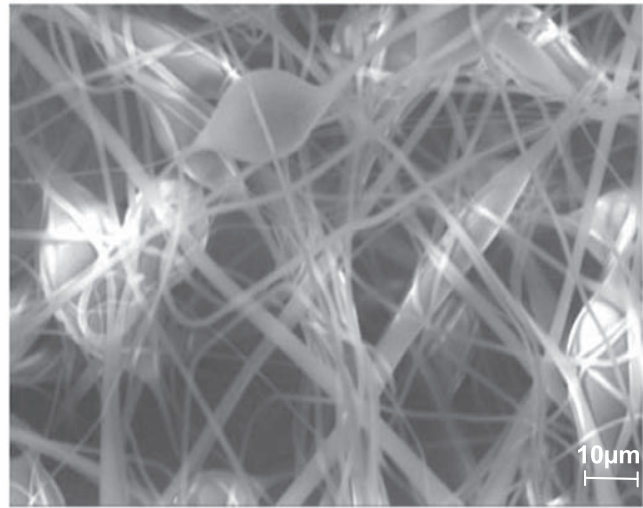

(1) $20 \% \mathrm{w} / \mathrm{v}, 20 \mathrm{kV}, \mathrm{WD}=10 \mathrm{~cm}$

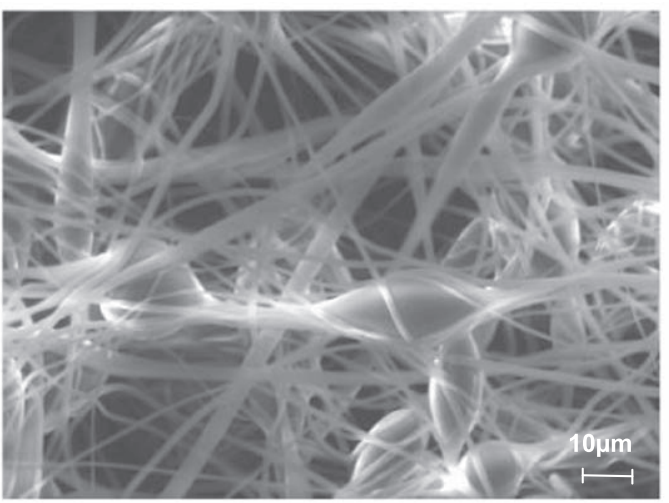

(j) $20 \% \mathrm{w} / \mathrm{v}, 15 \mathrm{kV}, \mathrm{WD}=10 \mathrm{~cm}$

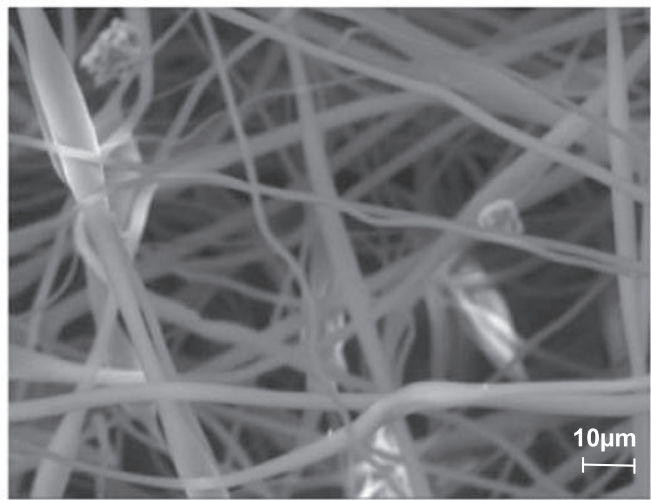

(m) $20 \% \mathrm{w} / \mathrm{v}, 25 \mathrm{kV}, \mathrm{WD}=10 \mathrm{~cm}$

Figure 3. (Continued.)

(d)-(f), whose viscosity increased from 0.9 to 1.0 Pa.s, and that exhibited Newtonian behavior like the other solutions ( 18 and $20 \% \mathrm{w} / \mathrm{v}$ ), there was more viscoelastic force to elongate the drops, forming fibers with fewer and smaller beads (figures 3(d)-(f)). However, there were still variations in the fiber diameters, mainly in the samples processed at 15 and $20 \mathrm{kV}$ (figures $3(\mathrm{~d})-(\mathrm{e})$ ).

Figure 3 (f) presents a mat obtained with the voltage of $25 \mathrm{kV}$, concentration of $20 \% \mathrm{w} / \mathrm{v}$ and WD of $5 \mathrm{~cm}$. The figure shows the formation of fibers without beads but still with some variation of the fiber diameter. For this concentration and a working distance of $10 \mathrm{~cm}$, we found the formation of mats with the presence of beads and many variations in the fiber diameter for all voltages (figures 3(j)-(m)). During the processing using the solution with $22 \% \mathrm{w} / \mathrm{v}$ PEI, and a WD of $5 \mathrm{~cm}$ (figures $3(\mathrm{~g})-(\mathrm{i})$ ), we found partial solidification of the solution on the tip of the needle. Thus, this processing condition was judged to be inappropriate. Even with a high value of viscosity (2.5 Pa.s), the mats exhibited a high occurrence of defects. When the working distance was $10 \mathrm{~cm}$ and the solution concentration was $22 \%$ (images not shown in this work) similar behavior was observed. White spots were observed, without microscopy, in the mats after processing and they occurred due to partial solidification of the solution on the tip of the needle.

For instance there are numerous reports in the literature describing the effects of solution concentration and polymer/solvent interaction on the results of electrospinning.

Rosic et al [18] produced mats by electrospinning solutions of poly (vinyl alcohol)/water with concentrations of 2 to $14 \mathrm{wt} \%$. However, nanofibers were not formed in their solutions with concentrations above $12 \mathrm{wt} \%$. Thus, there was a range of viscosities that resulted in the formation of nanofibers. Casasola et al [19] also correlated the viscosity with the diameter of the fibers in PLA solutions. They observed that the change in fiber morphology with increasing concentration can be attributed to competition between the surface tension and viscosity. An increase in the polymer concentration and solution viscosity result in more chain entanglements, an increase in the viscoelastic force resulting in nanofibres with fewer beads and larger fibers diameters. However, in very concentrated solutions, fibers were not formed. The Newtonian behavior also was found to be a requisite to produce electrospun mats in solutions with various polyesters in chloroform/ dimetylformamide [16] and in solutions of 5, 7 and $10 \% \mathrm{w} / \mathrm{v}$ of poly (D,L-lactic acid) with two systems of solvents: chloroform/dimetylformamide and chloroform/acetone [17]. Moon et al [11] produced PEI 

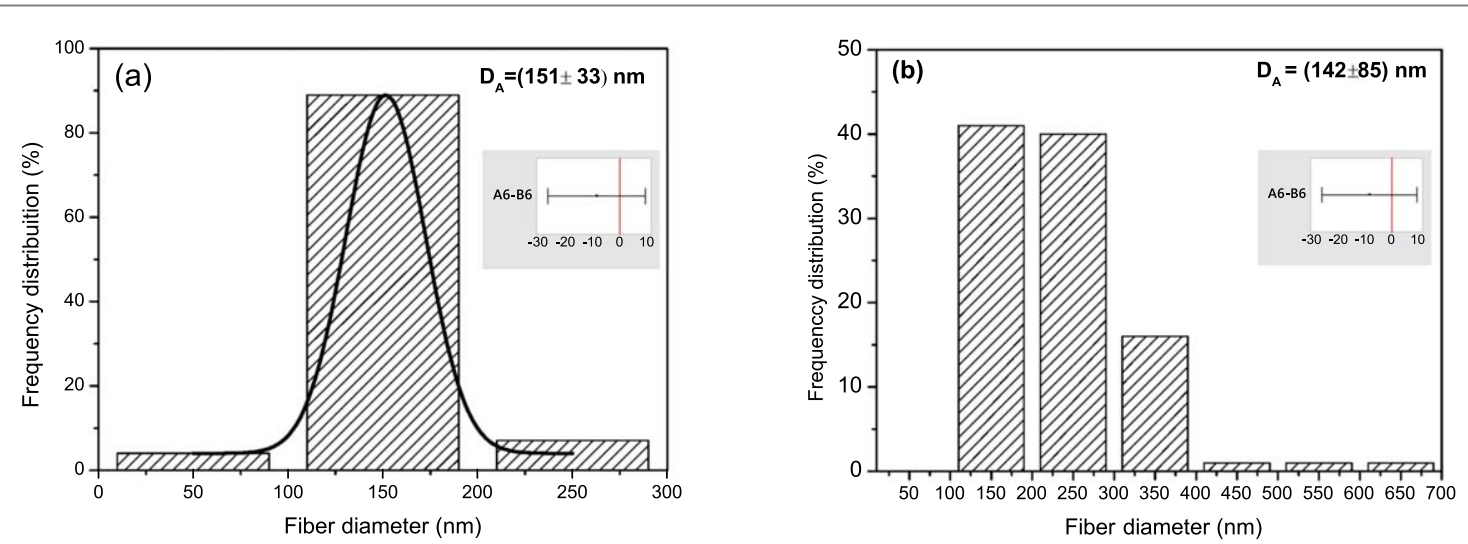

Figure 4. Diameter distribution of electrospun PEI processed from $20 \% \mathrm{w} / \mathrm{v}$ solution and $25 \mathrm{kV}$ with WD of (a) $5 \mathrm{~cm}$ (A6) and (b) $10 \mathrm{~cm}$ (B6) with one-way Anova and Tukey tests $(\mathrm{p}<0,05)$.

nanofibers without defects by electrospinning using solutions with NMP at $20 \mathrm{wt} \%$, with viscosity of 1.808 Pa.s. However, the mats produced with solutions of $18 \mathrm{wt} \%$ (0.932 Pa.s) had some beads and those produced with solutions of $15 \mathrm{wt} \%$ ( 0.336 Pa.s) had many beads. These viscosities corroborate the values found in this paper. In this work, the solution with a viscosity of $1.0 \mathrm{~Pa} . \mathrm{s}(20 \% \mathrm{w} / \mathrm{v})$ produced mats with only a few defects and some variation in the fiber diameter at $\mathrm{WD}=10 \mathrm{~cm}$ and mats with some variations of diameters and without defects at $\mathrm{WD}=5 \mathrm{~cm}$. The solution with a viscosity of 0.9 Pa.s $(18 \% \mathrm{w} / \mathrm{v})$ produced mats with many defects. Pseudoplastic behavior of the solutions of poly (vinyl alcohol) has also been shown to produce nanofibers without defects by electrospinning [20,21]. Thus, the solution concentration and the interaction of the polymer and solvent are the main parameters for good performance of the electrospinning process.

Figure 4 shows the diameter distributions of the electrospun PEI processed with $20 \% \mathrm{w} / \mathrm{v}$ solutions at $25 \mathrm{kV}$; (a) $5 \mathrm{~cm}$ (A6) and (b) $10 \mathrm{~cm}$ (B6) working distances. The values of the average diameters (DA) of the fibers and Tukey test are listed at the top of the graphs of the diameter distributions. As a function of the difference in working distance, figures 3(f), (m) show the influence of the electrical field (E) on the morphology and fiber diameter distribution in the mats. When work distance change of $10 \mathrm{~cm}$ to $5 \mathrm{~cm}$, fewer beads were formed, and less variation of the diameter was observed. Further, in accordance with figure 4(a) and (b), the standard deviation of the diameter was smaller $( \pm 33 \mathrm{~nm})$ than that of the mat with work distance of $10 \mathrm{~cm}( \pm 85 \mathrm{~nm})$ and the average diameter of fibers in this mat was slightly greater $(151 \mathrm{~nm})$ than that of the mat produced at $10 \mathrm{~cm}$ $(142 \mathrm{~nm})$. In accordance with Tukey test, the average diameters of the samples A6 and B6 did not change significantly. Thus, the morphology without beads and the smaller variation in the distribution of the diameter of the fiber were considered in this work to be the key parameters to produce PEI mats. The figure 4 shows that despite of the average diameter not be significantly different between the samples, the sample A6 has distribution of the diameter (between $10 \mathrm{~nm}$ to $300 \mathrm{~nm}$ ) narrower than sample B6 (between $100 \mathrm{~nm}$ and $700 \mathrm{~nm}$ ). Thus, processing a solution with concentration of $20 \% \mathrm{w} / \mathrm{v}$ of PEI/NMP, WD of $5 \mathrm{~cm}$ and voltage of $25 \mathrm{kV}$ were the most appropriate processing conditions to produce mats due this mat showed fewer defects and a narrow variation in the distribution of the diameter of the fibers.

The FT-IR spectra of electrospun (WD $=5 \mathrm{~cm}, 20 \% \mathrm{w} / \mathrm{v}$ ) and neat PEI are shown in figure 5 . The spectra in figures 5(a) and (b) show the following bands: $1780 \mathrm{~cm}^{-1}$ and $1721 \mathrm{~cm}^{-1}$ related to asymmetrical and symmetrical stretching of C-O groups (carbonyls bands); $1356 \mathrm{~cm}^{-1}$ and $744 \mathrm{~cm}^{-1}$ related to stretching and deformation of C-N groups and bands $1270 \mathrm{~cm}^{-1}$ and $1237 \mathrm{~cm}^{-1}$ related to stretching of ether groups in the aromatic rings. All these bands, characteristic of the PEI [2, 3, 22-24], were found in the electrospun PEI and neat PEI.

Conceição et al [2,3] investigated the effectiveness of PEI coatings on solid magnesium alloys. The coatings were formed by films obtained from the solutions of PEI with NMP and dimethylacetamide (DMAc). They analyzed the effect of residual solvent comparing neat PEI and a film of PEI/NMP with $20 \mathrm{wt} \%$ of PEI using FTIR. They observed that the spectra of the PEI/NMP film presented similar intensities for both the asymmetrical and the symmetrical carbonyl bands $\left(1780\right.$ and $\left.1725 \mathrm{~cm}^{-1}\right)$, two additional peaks with weak intensity together with the carbonyl bands, and, in the region of aromatic rings (between 1200 to $1300 \mathrm{~cm}^{-1}$ ), the presence of three peaks. For neat PEI, they found that the band at $1725 \mathrm{~cm}^{-1}$ was more intense than the band at $1780 \mathrm{~cm}^{-1}$ and there were only two peaks in the aromatic region. According to the authors, when the band at $1725 \mathrm{~cm}^{-1}$ is more intense than the band at $1780 \mathrm{~cm}^{-1}$, both imide rings are in the same plane, resulting in the presence of additional dipole moments. If both imides are not in the same plane in the molecule, the asymmetrical and symmetrical bands have similar intensities. Thus, in the films made from their solutions, the 

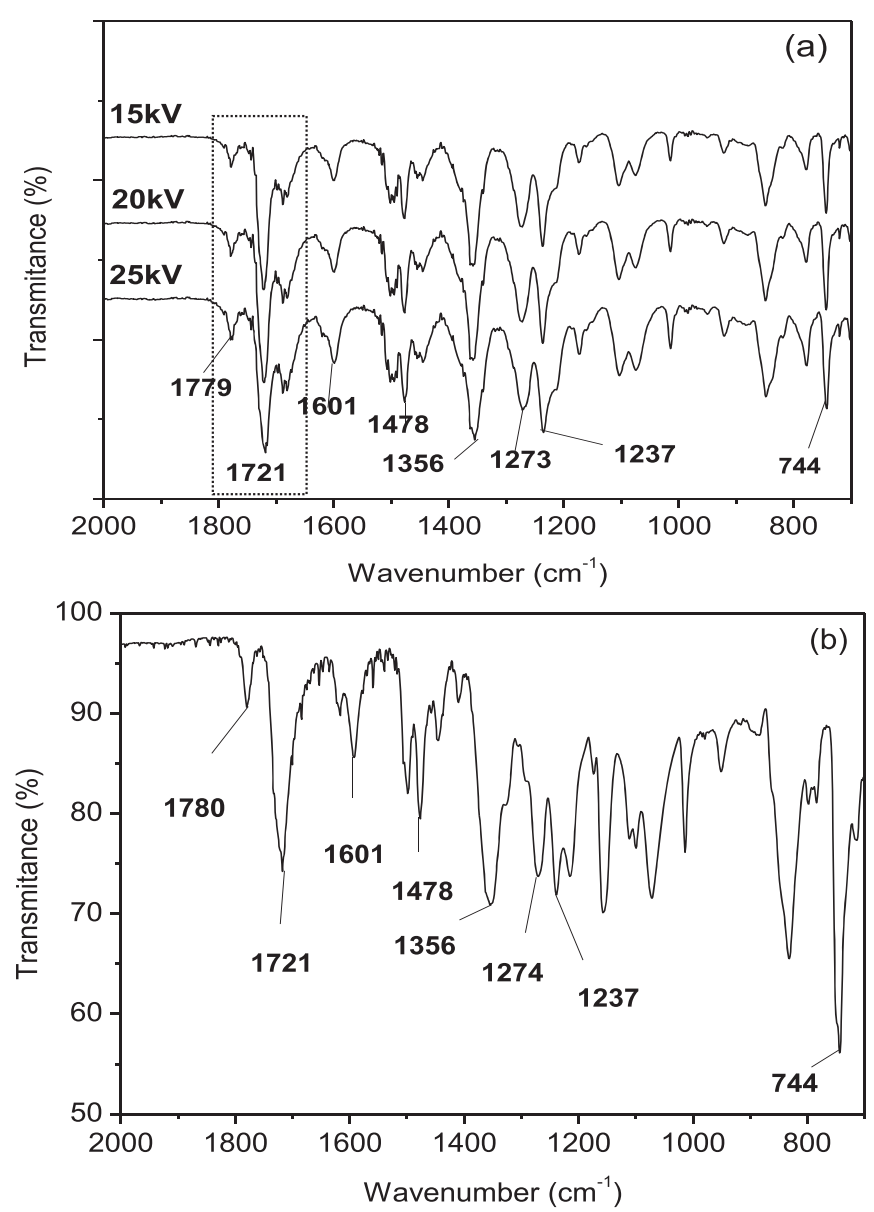

Figure 5. FT-IR spectra of (a) electrospun PEI and (b) neat PEI.

imides were not in the same plane whereas, in the neat PEI, the imides were in the same plane. Also, according to these authors, the change in number of peaks between 1200 and $1300 \mathrm{~cm}^{-1}$ suggested a distortion of the ether linkage angle (Ar-O-Ar). Based on their FTIR results, they suggested strong interactions of PEI with NMP. In figures 5(a)-(b), in the carbonyl region, the $1721 \mathrm{~cm}^{-1}$ band was much more intense than the band at $1780 \mathrm{~cm}^{-1}$ for both samples. This behavior indicated that the imide rings were in the same plane for electrospun PEI and neat PEI. We also observed a new peak at $1681 \mathrm{~cm}^{-1}$ only for electrospun PEI, as Conceição et al [2, 3] found in the films made with NMP and DMAc. This peak could be attributed to the presence of NMP in the electrospun PEI. We also found a change in signals between the electrospun PEI (figure 5(a)) and neat PEI (figure 5(b)) between 1200 and $1300 \mathrm{~cm}^{-1}$. There were three peaks in the neat PEI, as reported by Conceição et al [2,3], and two peaks with a shoulder at $1200 \mathrm{~cm}^{-1}$ in the electrospun PEI. Thus, the FTIR results suggest some interactions of PEI with NMP in the electrospun PEI. Analyses by FTIR were performed for all electrospun PEI and their spectra were all similar to the spectra shown in figure 5(a).

The thermal degradation behaviors of the mats and of neat PEI were analyzed by thermogravimetric analysis (TGA). The thermograms (TGA and DTGA) curves of the neat PEI and electrospun PEI processed at $\mathrm{WD}=5 \mathrm{~cm}$ with solution concentrations of (a) 18\% w/v (A1-A3), (b) 20\% w/v (A4-A6) and (c) 22\% w/v (A7-A9) are presented in figures 6(a)-(f). Table 2 shows the results of TGA and DTGA analyses for these samples.

There was one temperature of degradation, at $540{ }^{\circ} \mathrm{C}$, for the neat PEI. This behavior is in accordance with the literature [6, 25-27]. Some authors [26] attribute the PEI degradation temperature to the evolution of CO, $\mathrm{CO}_{2}$ and $\mathrm{CH}_{4}$ during heat treatment which causes cleavage of the rings of the PEI. The PEI fibers produced by electrospinning (A1-A9) showed two and, in some specimens, three maxima of decomposition rate, at various temperatures. The samples A1, A2 and A4 show loss weight in the range of 15 to $20 \%$ below $150{ }^{\circ} \mathrm{C}$. Also below this temperature, to the others mats can be observed high loss weight, in the range of $58 \%$ to $70 \%$. To the mats $\mathrm{A} 1, \mathrm{~A} 2$ and $\mathrm{A} 4$, this range temperature can be attributed to residual solvent or loss of water that remains adsorbed on the polymer fibers and were not completely evaporated during the electrospinning process. The boiling temperature of the $\mathrm{NMP}$ is $202{ }^{\circ} \mathrm{C}$. Thus, the degradation temperature observed in below $150{ }^{\circ} \mathrm{C}$ cannot be attributed to solvent evaporation. In this light, we attributed this degradation temperature range to the loss of water and other volatile organic components of the PEI because the sample was not previously dried. However, 

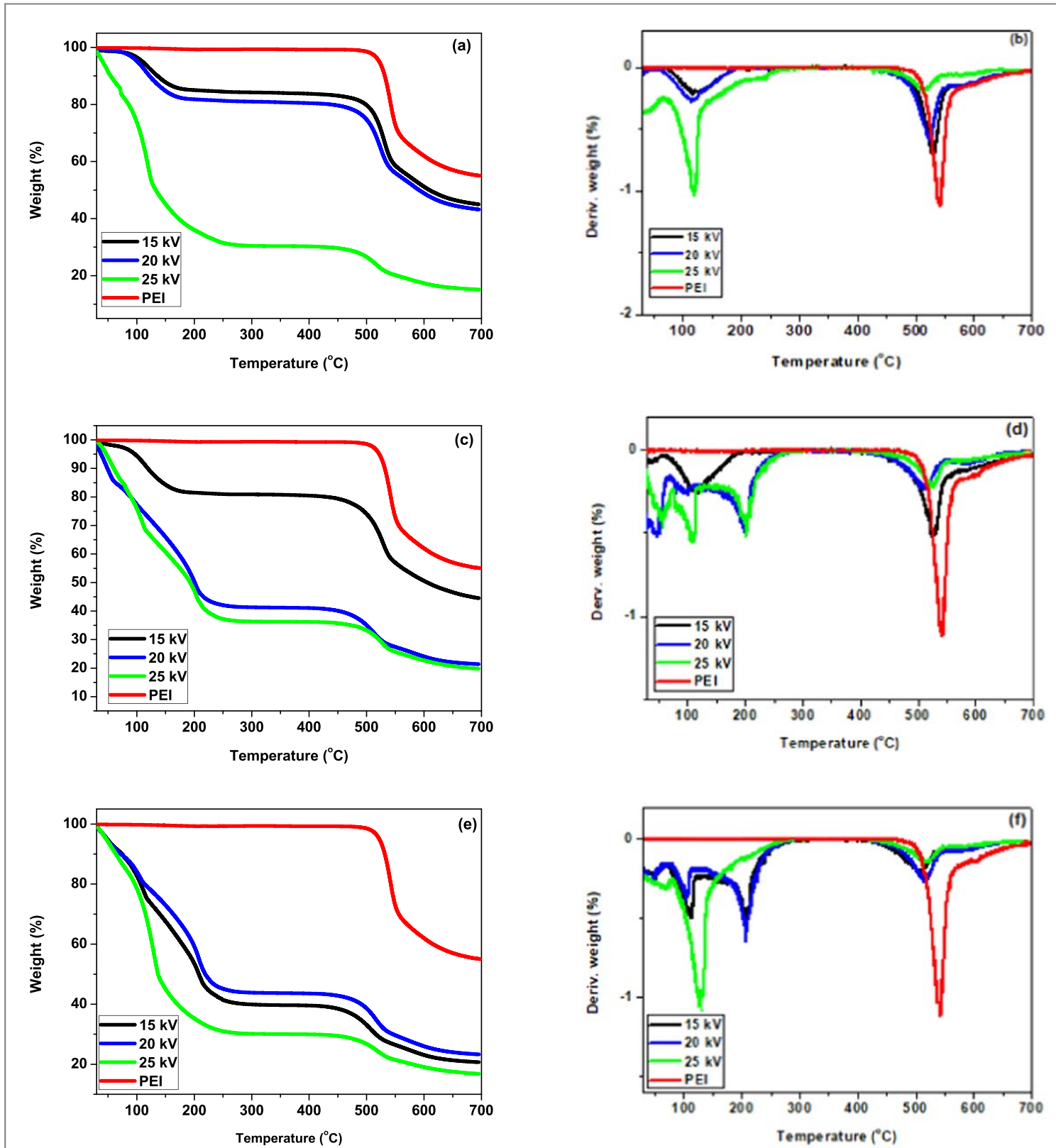

Figure 6. TGA and DTGA of the neat and electrospun PEI processed at WD $=5 \mathrm{~cm}$ at concentrations of ((a), (b)) $18 \% \mathrm{w} / \mathrm{v}$, (c), (d) $20 \% \mathrm{w} / \mathrm{v}$ and ((e), (f)) $22 \% \mathrm{w} / \mathrm{v}$.

Table 2. Decomposition temperatures and residual weight (R) of neat and electrospun PEI.

\begin{tabular}{lccccc}
\hline Sample & $\mathrm{T}_{1}$ & $\mathrm{~T}_{2}$ & $\mathrm{~T}_{3}$ & $\mathrm{~T}_{4}$ & $\% \mathrm{R}$ \\
\hline PEI & - & - & - & 540 & 56.2 \\
A1 & 120 & - & - & 530 & 35.0 \\
A2 & 115 & - & - & 525 & 43.0 \\
A3 & 119 & - & - & 517 & 15.0 \\
A4 & 117 & - & - & 529 & 45.1 \\
A5 & 98 & 205 & - & 512 & 21.9 \\
A6 & 79 & 110 & 205 & 528 & 20.5 \\
A7 & 105 & 207 & - & 516 & 21.5 \\
A8 & 110 & 205 & - & 505 & 24.0 \\
A9 & 131 & - & - & 517 & 17.8 \\
& & & & &
\end{tabular}

polyimides are hygroscopic polymer so the presence of water can be change the process of degradation of PEI to lower temperatures. The high loss of weight observed to the others mats possible can be attributed to the change of degradation process of the mats due to the presence of water that contributed to begin the process degradation 
of the polymer of the samples A3, A5-A9. In samples A5-A8, we observed a decomposition temperature in the range from $201{ }^{\circ} \mathrm{C}$ to $207^{\circ} \mathrm{C}$ that can be associated with residual solvent. We also observed decomposition temperatures of samples A1-A9 in the range from $505^{\circ} \mathrm{C}$ to $530{ }^{\circ} \mathrm{C}$ that are attributed to the final step of the polymer degradation. However, as reported previously, the degradation process of the polymer to the samples A3, A5-A9 begin before this temperature (below $150^{\circ} \mathrm{C}$ ). The residual weight of all electrospun samples was in the range from $45 \%$ to $15 \%$. It is possible to attribute this residual weight to the presence of aromatic rings in the structure of PEI. Han et al [6] found residual weight of electrospun PEI above $50 \%$ after TGA analysis $\left(20^{\circ} \mathrm{C}\right.$ to $\left.700{ }^{\circ} \mathrm{C}\right)$. Most authors have reported two decomposition temperatures in PEI nanofibers [5, 22, 28]. Choi et al [28], for instance, found two degradations steps in PEI nanofibers produced using 1,1,2-trichloroethane (TCE) as solvent. They attributed the weight loss in the range of $100{ }^{\circ} \mathrm{C}$ to $160{ }^{\circ} \mathrm{C}$ to the evaporation of the TCE. Li et al [25] also observed two decomposition temperatures in electrospun PEI. The first step was found between 100 and $200{ }^{\circ} \mathrm{C}$ with percentage of $2.6 \%$ and was attributed to the evaporation of volatiles and water. The second decomposition temperature occurred between 500 and $650{ }^{\circ} \mathrm{C}$. The authors proposed applications of these mats as filters used in high temperature environments. However, Salleh et al studied PEI membranes produced by solvent casting and found only one degradation temperature, between 480 and $570{ }^{\circ} \mathrm{C}$ [26]. The presence of one step was also reported by Wang et al [27] in membranes of PEI. They showed a degradation temperature in the range of $450{ }^{\circ} \mathrm{C}$ to $650{ }^{\circ} \mathrm{C}\left(\mathrm{T}_{\mathrm{d}}=508{ }^{\circ} \mathrm{C}\right)$. These two last works reported that the membranes were dried before TGA analyses and thus the first peak would not be expected.

The electrospun PEI (A1-A9) exhibited lower PEI decomposition temperatures and lower residual weights than neat PEI. Thus, the degradation behavior of the electrospun PEI was less stable. This could be because of the higher surface area the microfibers increased the effect of exposure to heat, and the presence of solvent and water created apparent instability at lower temperatures.

\section{Conclusions}

Mats formed with nanofibers with diameters around $150 \mathrm{~nm}$ were produced by electrospinning. The most appropriate processing conditions were: $20 \% \mathrm{w} / \mathrm{v}$ of PEI/NMP, WD of $5 \mathrm{~cm}$ and voltage of $25 \mathrm{kV}$ due this mat showed fewer defects and a narrow variation in the diameter of the fibers. It was found that in spite of very little increase in viscosity over that 0.9 to 1.0 Pa.s, it was possible to obtain significant improvement in the characteristics of the electrospun PEI to produce fibers having good morphologies. However, due to the higher loss of weight of this nanofiber below $150{ }^{\circ} \mathrm{C}$, this mat can be only be used in temperature in the range of $20^{\circ} \mathrm{C}$ to $50{ }^{\circ} \mathrm{C}$.

The electrospun PEI had lower degradation temperatures and exhibit degradation behavior different from that of the neat PEI. When compared with neat PEI, the electrospun samples showed a peak at $1681 \mathrm{~cm}^{-1}$ and the bands showed a doublet with a shoulder in the range of 1200 to $1300 \mathrm{~cm}^{-1}$ that could possibly be attributed to the presence and some interaction of the NMP with PEI in the electrospun nanofibers. In conclusion, nanofiber of PEI were produced and can be considered as a promising material to be evaluated some applications considering temperatures between 20 and $50{ }^{\circ} \mathrm{C}$ such as: sorbent for organochlorinated pesticides, to protect magnesium alloys against corrosion and for bio-hybrid organs like liver support system.

\section{Acknowledgments}

The authors acknowledge the financial support of the São Paulo Research Foundation (FAPESP, grant 2011/ 21061-2) and Conselho Nacional de Desenvolvimento Científico e Tecnológico (CNPq).

\section{ORCID iDs}

Lília Müller Guerrini (iD https://orcid.org/0000-0003-0518-1456

\section{References}

[1] Tan L-S 1999 Poly (ether imide) In Polymer Data Handbook ed J E Mark Edn. (New York: Oxford University Press) pp 471-8

[2] Conceição T F, Scharnagl N, Dietzel W and Kainer K U 2011 Corrosion protection of magnesium AZ31 alloy using poly(ether imide) [PEI] coatings prepared by the dip coating method: influence of solvent and substrate pre-treatment Corros. Sci. 53 338-46

[3] Conceição T F, Scharnagl N C, Blawert C, Dietzel W and Kainer K U 2010 Corrosion protection of magnesium alloy AZ31 sheets by spin coating process with poly(ether imide) [PEI] Corros. Sci. 52 2066-79

[4] Seifert B, Mihanetzis G, Groth T, Albrecht W, Richau K, Missirlis Y, Paul D and von Sengbusch G 2002 Polyetherimide: a new membrane-forming polymer for biomedical applications Artif. Organs 26 189-99 
[5] Huang Z-M, Zhang Y-Z, Kotaki M and Ramakrishna S 2003 A review on polymer nanofibers by electrospinning and their applications in nanocomposites Comp. Sci. Technol. 63 2223-53

[6] Han S O, Son W K, Cho D, Youk J H and Park Y H 2004 Preparation of porous ultra-fine fibres via selective thermal degradation of electrospun polyetherimide/poly(3-hidroxybutyrate-co-3-hydroxyvalerate) fibres Polym. Degrad. Stab. 86 257-62

[7] Seok H, Park C, Kim D Y and Jo S M 2012 Effect of post-process on physical properties of electrospun pei/pvdf blend nonwoven web Polym. Kor. 36 606-11

[8] Lee H J, Lim J M, Kim H W, Jeong S H, Eom S W, Hong Y T and Lee S Y 2016 Electrospun polyetherimide nanofiber mat-reinforced, permselective polyvinyl alcohol composite separator membranes: a membrane-driven step closer toward rechargeable zinc-air batteries J. Membr. Sci., V. $499526-37$

[9] VojtĔch A, Pavel H, Michal K and Martin S 2016 Polyetherimide nanofibres as sorbents for organochlorinated pesticides determination J. Nanomater., V. Article ID $139034520161-7$

[10] Zhang Q, Xia K, Liu L, Liu Y C, Zhang C, Liu X, Xu H, Chen S J and Chen J D 2013 Preparation of PVA/DTC nanofibers and their adsorption performance of lead ion Chem. J. Chin. Univ. 34 2667-73

[11] Moon S, Choi J and Farris R J 2008 Preparation of Aligned Polyetherimide Fiber by Electrospinning J. Appl. Polym. Sci. 109 691-4

[12] Krasteva V, Pehlivanova V, Seifert B, Luetzow K, Tsoneva I, Richau K, Lendlein A and Tzoneva R 2011 Influence of AC electric fields on the adsorption of plasma proteins into nanofibres biomaterials Compt. Rend. Acad. Bulg. Sci. 64 535-44

[13] Zhao L J, Sui G and Yang X P 2012 Study on structure and dielectric properties of electrospun polyetherimide fibrous membranes Acta Polym. Sinica. 12 1409-16

[14] Fashandi H and Karimi M 2014 Comparative studies on the solvent quality and atmosphere humidity for electrospinning of nanoporous polyetherimide fibers Ind. Eng. Chem. Res. 53 235-45

[15] Ghasemi-Mobarakeh L, Semnani D and Morshed M 2007 A novel method for porosity measurement of various surface layers of nanofibers mat using image analysis for tissue engineering applications J. Appl. Polym. Sci. 106 2536-42

[16] McKee M G, Wilkes G L, Colby R H and Timothy E L 2004 Correlations of solution rheology with electrospun fiber formation of linear and branched polyesters Macromolecules 37 1760-7

[17] Branciforti M C, Custodio T A, Guerrini L M, Avérous L and Bretas R E S 2009 Characterization of nano-structured poly(D,L-lactic acid) nonwoven mats obtained from different solutions by electrospinning J. Macromol. Sci. Part B Phys. 481222 - 1240

[18] Rosic R, Pelipenko J, Kristl J, Kocbek P, Rogac M B and Baumgartner S 2013 Physical characteristics of poly (vinyl alcohol) solutions in relation to electrospun nanofiber formation Eur. Polym. J. 49 290-8

[19] Casasola R, Thomas N L, Trybala A and Georgiadou S 2014 Electrospun poly lactic acid (PLA) fibres: effect of different solvent systems on fibre morphology and diameter Polymer 55 4728-37

[20] Atabey E et al 2012 Fluorescent electrospun polyvinyl alcohol/CdSe@ZnS nanocomposite fibers J. Compos. Mater. 47 3175-85

[21] Guerrini L M, Oliveira M P, Branciforti M C, Custódio T A and Bretas R E S 2009 Thermal and structural characterization of nanofibers of poly(vinyl alcohol) produced by electrospinning J. Appl. Polym. Sci. 112 1680-7

[22] Jang J and Sim K 1998 Crystallization behavior in poly(etherimide)/poly(butylene terephthalate) blends using a spectroscopic method Polym. Testing 507-21

[23] Choudhury A 2010 Dielectric and piezoelectric properties of polyetherimide/ $\mathrm{BaTi}_{3}$ nanocomposites Mat. Chem. Phys. 121 280-5

[24] Romero A I, Parentis M L, Habert A C and Gonzo E E 2011 Synthesis of polyetherimide/silica hybrid membranes by the sol-gel process: influence of the reaction conditions on the membrane properties J. Mat. Sci. 46 4701-9

[25] Li X, Wang N, Fan G, Yu J, Gao J, Sun G and Ding B 2015 Electreted polyetherimide-silica fibrous membranes for enhanced filtration of fine particles J. Coll. Interf. Sci. $43912-12$

[26] Salleh W N W and Ismail A F 2011 Carbon hollow fiber membranes derived from PEI/PVP for gas separation Sep. Purif. Tech. 80 541-8

[27] Wang Y, Jiang L, Matsuurac T, Chung T S and Goh S H 2008 Investigation of the fundamental differences between polyamide-imide (PAI) and polyetherimide (PEI) membranes for isopropanol dehydration via pervaporation J. Membr. Sci. 318 217-26

[28] Choi S-S, Lee S G and Im S S 2004 Formation of interfiber bonding in electrospun poly(etherimide) nanofiber web J. Mat. Sci. 39 $1511-3$ 